\title{
生物信息流的人工操纵一一作物病虫害导向性 防控的新科学
}

\author{
钱韦 ${ }^{1}$, 陈晓亚 ${ }^{2}$, 方荣祥 ${ }^{1}$, 康乐 $3^{*}$
}

1. 中国科学院微生物研究所, 植物基因组学国家重点实验室, 北京 100101 ;

2. 中国科学院上海植物生理生态研究所, 植物分子遗传学国家重点实验室, 上海 230032;

3. 中国科学院动物研究所, 农业虫害鼠害综合治理研究国家重点实验室, 北京 100101

* 联系人, E-mail: 1kang@ioz.ac.cn

收稿日期: 2017-09-14; 网络版发表日期: 2017-09-17

农业是人类最伟大的创造发明之一. 依靠不断创新与革命的农业技术，人类逐步摆脱了食物贵乏对人口 数量的限制, 并且得以在物质丰富的基础上建立起了地球文明. 特别是自 20 世纪绿色革命时代以来, 以化肥、 除草剂、杀菌剂、杀虫剂、抗生素和植物生长促进剂为代表的现代农业技术大幅提高了世界粮食的生产效率, 为新技术革命和信息时代的到来创造了先决条件. 然而，这些生产技术应用的同时也带来了显著的副作用: 例如，中国虽然用世界 7\%的耕地养活了超过 $22 \%$ 的人口，实现了了不起的社会发展成就，但为了防治病虫害 对作物产量的严重威胁, 我们却施用了全世界超过 $1 / 3$ 的农药, 农药用量排名全球第一. 当前, 频繁发生的农 药滥用事件严重影响了环境质量和人类健康，成为政府及全社会高度关注的民生热点问题. 因此，如何继续 发展绿色、精准和环境友好的作物病虫害防控技术已经成为保证“舌尖上的安全”的当务之急.

虽然农药和作物抗病新品种的培育是不扣不折的应用技术，但其创新与发展却离不开生命科学基础研究 的指引和关键学术思想的突破. 当前使用的化学农药、抗生素等多以病原微生物或有害昆虫的基础代谢系统 作为攻击靶点, 主要防控目标是有效杀灭. 这固然能够在短期内迅速达到防控目标, 但除了前述缺点外, 病虫 害在强大的自然选择压力下也容易快速进化出耐药性，使农药应用不具可持续性. 在这种情况下，能否改变 以“杀灭”为核心的病虫害防控思路？通过人为“操纵”病虫害的行为模式，在达到降低灾害威胁目标的同时， 平衡病害防控与环境污染之间的矛盾?

如果我们仔细思考作物-病原微生物-昆虫之间的相互关系, 就能发现：以“杀灭”为目标的防控思路忽视了 物种之间存在的固有生态关系. 事实上，在作物-病原微生物-昆虫之间存在着广泛的信息交流与联系，而这些 种间生物信息的产生、识别、信号转导、级联放大和细胞对信息的处理，是决定寄生、互惠、捕食和互利等 生态关系的重要纽带. 举实例而言, 为什么在数量众多的土壤微生物类群中, 只有极少的一部分类群成为植 物病原? 它们是如何识别特定植物寄主的? 又如，在农业生产中，像水稻条纹叶枯病、黑条矮缩病这样的植物 病毒病害非常难以防治. 一旦爆发成灾基本无药可治，是近年来危害作物生产的巨大隐患. 科学家发现，70\% 以上的动、植物病毒病害是通过媒介昆虫来传播. 病毒寄生于昆虫体内, 在昆虫取食作物的过程中完成寄主转 换, 并且在条件适合时种群爆发, 发生大面积的病害. 上述过程中有很多关键科学问题是不清楚的, 如病毒在 昆虫体内的生存状态、病毒与昆虫的共生互惠关系、感染植物过程中昆虫唾液发挥的核心功能、昆虫识别植 物寄主的原理等. 如果科学家理解了昆虫媒介传播病毒的过程与机制, 就能够设计针对性的防控方法, 阻断 
病毒在昆虫寄主中的生活史, 从而达到高效、特异防控的目的. 除病虫害防控以外, 我们希望特别指出作物病原微生物-昆虫相互关系的研究也是当前生命科学的领域前沿之一. 这一领域产出的重大科学成果有效地带 动了基础生命科学和通用生物技术的快速发展. 例如, 农杆菌介导的植物转化技术、RNAi 干扰及基因沉默技 术、TALEN 基因组编辑技术、真核生物免疫受体的发现与功能分析等突破性研究, 公认都是由本领域率先孕 育和完成的.

作物-病原微生物-昆虫种间信息流的相关研究涉及到多个学科的汇聚和协作攻关，在科研组织形式上需 要做出创新性的改变. 为此, 中国科学院于 2014 年启动了“作物病虫害的导向性防控”战略性先导科技专项, 组织来自于全院植物学、微生物学、昆虫学、化学生物学、基因组学等多个领域的优势研究队伍，在“生物信 息流及病虫害行为操纵”这一总体学术思想的统领下开展长期研究. 该项目的目标是：在阐明作物病虫害发生 过程中生物信息流的作用的基础上，发展先进防控技术，对我国主要作物病虫害进行导向性防控. 项目执行 数年来已经在基础与应用两方面取得了多项重大突破成果，其中包括在国际上首先实现水稻、小麦的基因组 编辑并培育出抗病植株, 发现非编码 RNA 从植物向病原真菌的转移并培育出高抗黄萎病的棉花品系, 发现昆 虫群聚的新型调控机制, 发现植物一病原微生物相互识别的分子过程等. 专项系列成果已经发表于 Science, PNAS, Cell Host Microbiology, Nature Plant, Nature Communications, PLoS Pathogens 等国际刊物上, 部分工作 得到了 MIT Technology Review, Nature 和 Science 等杂志的评论和高度关注. 同时, 专项在项目创新管理模式、 共享数据、共享技术和设备平台建设和青年人才培养举荐方面取得了重要进展.

为了集中展示专项团队的研究成果，《中国科学：生命科学》于 2017 年 9 月组织出版了“生物信息流与作 物病虫害导向性防控专辑”. 本专辑由康乐、陈晓亚和方荣祥院士担任特邀编辑, 共发表该专项团队的 12 篇综 述、原始研究论文和快报, 内容广泛涵盖了从植物抗病机制、病原真菌、病原细菌、昆虫-植物相互关系等领 域前沿. 其中, 植物天然免疫系统研究的热点之一是寄主植物细胞如何利用模式识别受体(PRR)来识别病原微 生物细胞表面的相关分子模式(PAMP/MAMP). 中国科学院微生物研究所张杰团队 ${ }^{[1]}$ 系统回顾了这一领域的研 究进展, 并特别强调诱㱗蛋白(decoy)在抗病过程和未来植物抗病育种中的作用. 邱金龙团队 ${ }^{[2]}$ 发现植物激素 脱落酸(ABA)负调控植物的抗病性. 由于 ABA 在调节植物衰老方面起关键作用, 这项研究表明植物发育过程 与病原感染之间存在紧密的联系，值得深入分析.

棉花是我国新疆地区大面积种植的栽培作物，其生产对于维持当地经济、社会发展具有特别重要的意义. 在棉花病害中, 由大丽轮枝菌导致的黄萎病是一种破坏性极强的病害, 造成严重的产量损失. 由于缺乏抗源, 如何控制这种病害是棉花生产中难以解决的问题. 中国科学院微生物研究所夏桂先、王海云团队 ${ }^{[3]}$ 发现, 过表 达棉花 profilin 基因 GhPFN2 不仅能够重组植物的肌动蛋白结构, 而且显著提高了植物抗大丽轮枝菌的能力. 这项工作意味着可以通过操纵植物细胞骨架系统, 获得兼备优质和高抗病的棉花品种. 郭惠珊团队 ${ }^{[4]}$ 利用病 原微生物的表面分子模式，如 flg22 和 nlp20 处理棉花，并分析了病程相关蛋白基因(PR genes)的表达水平，这 些基因可作为棉花抗病性时的免疫应答分子标记，在未来研究中发挥作用.

在农业害虫中，蚜虫通过直接取食植物和作为媒介传播病毒，造成了严重的农业损失. 但是，有关蚜虫的 基础研究仍然比较薄弱. 绿盲蝽(Apolygus lucorum) 能够寄生于 150 多种植物上, 危害农业生产. 中国科学院上 海植物生理生态研究所陈晓亚、毛颖波团队 ${ }^{[5]}$ 采用高通量 RNA-seq 方法比较了 A. lucorum 的转录组, 为深入 研究这种害虫的成灾机理提供了必要的组学数据. 中国科学院动物研究所孙江华、赵莉萄团队 ${ }^{[6]}$ 研究了内生真 菌 Beauveria bassiana 感染后天牛 Monochamus alternatus 的免疫应答反应. 他们发现 Toll 和 IMD 途径在天牛 的免疫反应中发挥主导作用. 在该团队发表的快报中 ${ }^{[7]}$, 发现来自中国和北美的松材线虫在发育上具有重要 差异. 此外, 由于近年来发生的全球气候变化对昆虫行为具有深远的影响. 戈峰团队 ${ }^{[8]}$ 综述了植物感染虫传病 毒的过程中, $\mathrm{CO}_{2}$ 或 $\mathrm{O}_{3}$ 升高对病毒传播的生物学影响, 强调了植物激素在此过程中的重要作用.

在作物一病原微生物一昆虫的相互作用过程中, 生物信息的跨界信号交流是领域前沿之一.中国科学院 微生物研究所方荣祥、贾燕涛团队 ${ }^{[9]}$ 综述了植物与微生物之间通过信息化合物进行跨种间通讯的研究进展, 其 中特别强调微生物群体感应信号在跨界信号交流中的重要研究意义. 中国科学院动物研究所孙江华、鲁敏团 
队 ${ }^{[10]}$ 发现, 细菌产生的挥发物会影响昆虫共生真菌的拮抗作用, 表明昆虫的细菌共生体能够抑制真菌生长, 从而使寄主受益. 中国科学院武汉病毒研究所胡志红、王曼丽团队 ${ }^{[1]]}$ 综述了 PIF 功能的研究进展, 为深入研究 昆虫与病毒之间的分子相互作用提供了重要的信息. 最后, 中国科学院动物研究所张知涁团队 ${ }^{[12]}$ 调查了野鼠 种群的动态变化, 揭示了食物供给状况影响植物群落和野鼠种群大小的可能机制.

中国是世界上首屈一指的农业大国，但却不是农业强国，历史上曾经多次遭受作物病虫害导致的严重影 响. 然而, 在抗病虫害生物技术方面, 不可能永远模仿和跟踪国外同行的先进成果. 由于中国农业发展模式有 其鲜明的特点和多样性，在世界上也不可能找到一个可以作为标杆的参照. 随着国家对农业基础研究投入的 增加和国内优势研究团队的迅速成长, 我国在病虫病防控基础与应用研究领域已经具有较高的国际显示度. 我们希望本专辑的出版能够吸引国家科技政策制定者、青年科学家和同行专家, 共同关注这一战略科学领域 的长期发展, 从而为保障国家粮食安全和食品安全做出前瞻性的贡献.

\section{参考文献}

1 孙丽璠, 秦君, 王凯伦, 等. 基于模式识别受体和人工设计诱饵蛋白扩展植物识别特异性. 中国科学: 生命科学, 2017, 47: 893-902

2 肖翔, 程曦, 尹康权, 等. 脱落酸负调控拟南芥对白粉菌的穿透后抗性. 中国科学: 生命科学, 2017, 47: 949-959

3 王文燕, 孙永铎, 韩利波, 等. 过量表达 GhPFN2 基因增强棉花对大丽轮枝菌的抗性. 中国科学: 生命科学, 2017, 47: 970-976

4 杜旋, 王胜, 高峰, 等. 棉花 PR 基因感应大丽轮枝菌病原相关分子模式的表达分析. 中国科学: 生命科学, 2017, 47: 960-969

5 陈殿阳, 陈芳艳, 陈春雨, 等. 棉花主要害虫绿盲蝽转录组动态变化特征及其与棉铃虫和棉蚜的比较分析. 中国科学: 生命科学, 2017, 47: 936-948

6 张伟, 孟洁, 宁静, 等. 松墨天牛对共生真菌和病原真菌的差异性免疫响应. 中国科学: 生命科学, 2017, 47: 988-996

7 张帅, 宁静, 张伟, 等. 实验室条件下中国和北美松材线虫(Bursaphelenchus xylophilus)(Tylenchida: Aphelenchoididae)分离株之间 的发育差异. 中国科学: 生命科学, 2017, 47: 1007-1010

8 郭洪刚, 王世藩, 戈峰. 植物激素信号调控的“植物病毒-植物-媒介昆虫”三者互作对温室气体变化的响应. 中国科学: 生命科学, 2017, 47: 928-935

9 暤金红, 方荣祥, 贾燕涛. 植物与微生物之间的跨界信号调控. 中国科学: 生命科学, 2017, 47: 903-916

10 王闪闪, 周方园, 王波, 等. 细菌挥发物减缓伴生真菌对红脂大小臯幼虫的不利作用. 中国科学: 生命科学, 2017, 47: 977-987

11 汪习, 刘晓萍, George Alliwa Makalliwa, 等. 口服感染因子: 杆状病毒编码的一种复杂而进化保守的入侵机器. 中国科学: 生命 科学, 2017, 47: 917-927

12 殷宝法, 李国梁, 宛新荣, 等. 大型野外围栏实验揭示增食对布氏田鼠种群动态的复杂效应. 中国科学: 生命科学, 2017, 47: 997-1006 


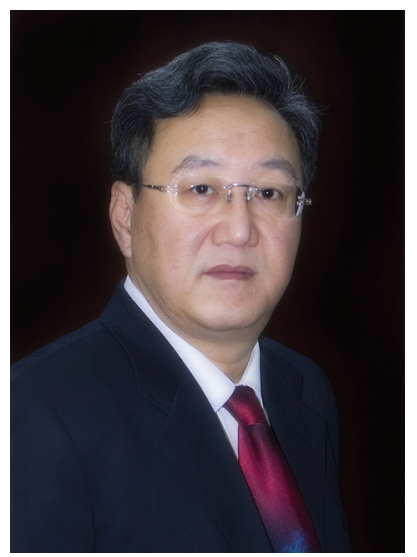

康乐 博士, 河北大学校长, 中国科学院动物研究所研究员, 博士生导师, 中科院院士, 发展中国家科学院院士(TWAS). 主要从事昆虫学与生态基因组学研 究, 整合分子生物学、基因组学、生理学和昆虫行为分析等多种方法, 分析昆虫 适应环境变化和自然选择压力的生态学问题. 已经发表了近 200 篇国际期刊论文, 代表性成果发表在 Science, PNAS, Nature Communications, PLoS Genetics, PLoS Pathogens, Genome Biology 等期刊上. 曾受邀在 Annual Review of Entomology, Philosophical Transactions of the Royal Society 等著名期刊上发表研究综述. 同时, 他还担任 International Journal Insect Science 主编, Protein \& Cell 副主编, Zoological Research 副主编, Science China Life Sciences 等多个国际期刊编委.

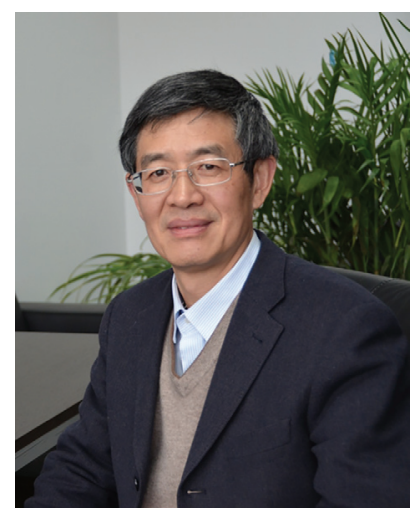

陈晓亚 博士, 中国科学院上海植物生理生态研究所研究员, 博士生导师, 中国科学院院士, 发展中国家科学院院士(TWAS). 目前担任上海辰山植物科学研 究中心主任, 中国植物生物学会理事长, Science Bulletin 主编, Science China Life Sciences 编委. 主要从事植物次生代谢、植物一昆虫相互作用和棉花纤维发育研究. 对棉花、青蒿、拟南芥和丹参中萜类物质的生物合成和调控进行了深入研究. 已 经发表研究论文 100 余篇, 刊载在 Nature Biotechnology, Nature Communications, Plant Cell, Molecular Plant, PLoS Genetics 等国际期刊上.

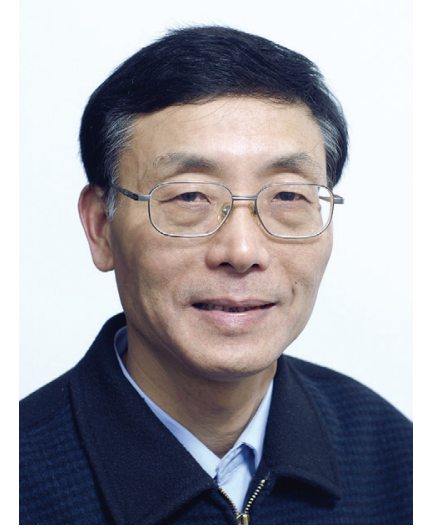

方荣祥 中国科学院微生物研究所研究员, 博士生导师, 中国科学院院士, 发展中国家科学院院士(TWAS). 第 11, 12 届全国政协委员. 长期从事植物病毒分 子生物学和植物生物技术研究, 主要研究方向包括昆虫一作物一病毒相互作用、 RNA 沉默和植物分子生物学. 早期完成了花椰菜花叶病毒和水稻黄矮病毒基因组 全序列分析, 鉴定了植物弹状病毒的运动蛋白. 研制成同时抗烟草花叶病毒和黄 瓜花叶病毒的转基因烟草, 在种植时间和规模上曾居国际领先; 在植物生物技术 的基础研究方面, 分析和改造了花椰菜花叶病毒 $35 \mathrm{~S}$ 启动子, 研究结果被广泛应 用; 阐明了利用人工小 RNA 抵抗植物病毒侵染的新策略; 阐明水稻条纹叶枯病毒 经媒介昆虫的卵传机制. 已经发表研究论文近 200 篇, 代表性成果发表于 Cell, Plant Cell, PNAS, PLoS Pathogens and Journal of Virology 等期刊上. 